\title{
Correlates of Safe Disposal of Children's Stool in Nigeria: Evidence from 2018 Demographic and Health Survey
}

\author{
Sulaimon T. Adedokun, \\ Amos O. Oyedokun, \\ Olufunmilayo O. Banjo,
}

Department of Demography and Social Statistics, Obafemi Awolowo University, Ile-Ife, Nigeria

Doi:10.19044/esj.2020.v16n24p351 URL:http://dx.doi.org/10.19044/esj.2020.v16n24p351

\begin{abstract}
Unsafe Stool disposal has been linked to high under-five morbidity and mortality in many low and middle-income countries. This paper focuses on examining the prevalence of safe disposal of stools in Nigeria and the factors affecting such behaviour. The most-recent Nigeria Demographic and Health Survey 2018 (NDHS) Child's dataset was used for the analysis in this study. Sample size of 7,834 children under age five was analysed. Percentages and frequencies, chi-square test of association, and binary logistic regression were employed for the statistical analysis. Findings show that a little above half of the women respondents reported safe disposal of stool of their under-five children in the study area (53\%). Specifically, the odds of having stool safely disposed increased by 133 percent for children whose household wealth index falls within the richer category (adjusted Odd Ratio (aOR): 2.33; $<<0.001$ ), reduced by 17 percent for children whose mothers are working (aOR: 0.83; $\mathrm{p}<0.05$ ), increased for children whose mothers are residing only in North-East and North-West $(\mathrm{p}<0.001)$, increased by 19 percent for children whose mothers were exposed to media exposure to mass media (aOR: 1.19; $\mathrm{p}<0.05$ ), reduced by 24 percent for women whose children are of first birth order (aOR: $0.76 ; \mathrm{p}<0.05$ ), reduced by 31 percent for women whose children are of small size at birth (aOR: 0.69; $\mathrm{p}<0.001$ ), increased by 66 percent for women who reported that distance to facility was not a problem (aOR: 1.66; $\mathrm{p}<0.001$ ), reduced by 19 percent for women who delivered their children at an health centre (aOR: $0.81 ; \mathrm{p}<0.05)$, and increased by 114 percent for women who used improved toilet facility (aOR: 2.14; $\mathrm{p}<0.001$ ). This study concludes that a combination of socioeconomic, maternal, child's and environmental factors are the correlates of safe disposal of stool among women with under-five
\end{abstract}


children in Nigeria. It should therefore be prioritised for interventions aimed at reducing high under-five morbidity and mortality in Nigeria.

Keywords: Correlates, Stool, Safe, Disposal, Under-five, Morbidity, Children, Nigeria

\section{Introduction}

Disposal of children's stool is an important component of global Water, Sanitation and Hygiene (WASH) initiative (Nkoka, 2020). Diarrhoea resulting from unsafe disposal of stool is found to be one of the leading causes of morbidity and mortality among under-five (U5) children globally (You, Hug, \& Chen, 2014). Safe disposal of children's stool refers to “putting/rinsing stools into a sanitation facility” (WHO/UNICEF, 2006, p.7). Hence, safe children's stool disposal in general, and the disposal of U5 children's stool in particular, is critical for ensuring the Sustainable Development Goal (SDG) 6, which seeks to ensure that water and sanitation is available and sustainably managed for all (WHO, 2015).

Nigeria like many other low- and medium-income countries still lag behind in stool disposal of under-five children, thereby resulting in many cases of diarrhoea and other sanitation-related morbidity and mortality (NPC \& ICF, 2019). Nigeria is the most populous country in Africa with a population of about 200 million having U5 mortality rate of almost 120 deaths per thousand live births (National Bureau of Statistics, 2017; UNICEF, 2020; World Population Review, 2020). Despite the fact that a number of studies have examined factors associated with diarrhoea in under-five children in many sub-Saharan Africa including Nigeria, it is not yet clear what factors are associated with U5 children's stool disposal. This study therefore seeks to examine the correlates of U5 children's stool disposal using a very recent nationally-representative data.

\section{Literature Review}

Most of the existing studies aimed at improving the health of U5 children have focused more on the incidence of diarrhoea among them. This is with little attention being paid to the disposal of their stool, which is a principal factor in the incidence of diarrhoea among them. For example, Mulatya and Ochieng (2020) examined factors associated with the burden of morbidity resulting from under-five children with diarrhoea in Kenya. Yet, there is no information on stool's disposal and the contribution to the incidence of diarrhoea among under-five children in the population. A similar study was also conducted in Uganda by Omona, Malinga, Opoke, Openy, and Opiro (2020). Some of the factors that significantly predicted diarrhoea morbidity among under-five children were family size, child weaning time, and age of 
child's caretaker among other factors. Ferede (2020) also examined risk factors associated with diarrhoea in under-five children in Ethiopia and found that age, sex, and birth order of children were significantly associated with incidence of diarrhoea. Other factors identified were current age of mothers and sharing toilet facilities with other families in the household.

Furthermore, Onyilokwu, Aye, Adamu, and Lawan (2020) conducted a study in Benue state, Nigeria, to identify epidemiological factors responsible for diarrhoea in 0-5 children in selected health facilities in the State. Although the study found a significant association between children's age and the incidence of diarrhoea, hygienic practices were also identified as contributory factors responsible for low incidence of diarrhoea in infants. Thus, it became imperative due to the sparse information about handling of stools among under-five children to consider the extent of safe and unsafe under-five children's stool disposal in Nigeria and the associated factors using a nationally-representative data.

Bawankule, Singh, Kumar, and Pedgaonkar (2017) considered the association between the disposal of children's stool and the incidence of diarrhoea among them in India. Findings from their study showed a high incidence of unsafe children's stool disposal and found a wide rural-urban gap in the population. Some of the determinants of unsafe stool disposal were child's age, media exposure, mother's illiteracy, household wealth index, and the tribe of household head among others. Aliyu and Tukur (2019), using the 2013 NDHS dataset, found some factors associated with children's stool disposal in Nigeria. Some of these factors are the age of mother, maternal education level, household wealth index, religion, source of water, and type of toilet facility.

Although some of the studies reviewed above gave a hint to the issue of disposal of stools of under 5 children, there is the need to further explore other correlates around the disposal of under 5 children's stool in Nigeria using a more recent nationally-representative data. This study therefore seeks to answer the following research questions: (i) What is the extent of safe and unsafe disposal of under 5 children's stool in Nigeria? (ii) What are the maternal and environmental factors contributing to stool disposal among under 5 children in Nigeria? and (iii) What are the other factors responsible for the safe disposal of under-five children's stool in the study area?

\section{Data and Methods}

This study used children's data set from 2018 Nigeria Demographic and Health Survey. The survey is cross-sectional and provides information on health and population characteristics of women and children. The sample for the survey involved two stages. In the first stage, the country was divided into states and each state was divided into local government areas. In each local 
government area, communities or clusters were carved out. From these clusters, 1,400 enumeration areas (EAs) were selected. In each enumeration area, a household listing exercise was carried out in order to identify eligible households for interview. In the second stage, a fixed number of 30 households were in every cluster through systematic sampling method. This resulted in a total sample of 42,000 households. Thereafter, eligible households were selected through computer programming. Women age 15-49 years who were either permanent residents of the chosen household or visitors in the night before the survey were eligible for interview. A face-to-face interview was conducted through administration of questionnaires. The questionnaires included questions on socioeconomic characteristics, reproductive history, antenatal, delivery and postnatal care, women's minimum dietary diversity, vaccinations and childhood illnesses, child's stool disposal methods, maternal mortality, and domestic violence among others (NPC \& ICF, 2019).

\section{Outcome Variable}

The outcome variable has two categories: safe child's stool disposal and unsafe child's stool disposal. Safe child's stool disposal is defined as a situation where a child uses toilet/latrine or where the child's stool is rinsed/put in the toilet/latrine or buried. Any other means of disposing child's stool apart from the above is regarded as unsafe child's stool disposal (WHO/UNICEF, 2006; Nkoka, 2020).

\section{Independent Variables}

The following independent variables were considered in the study: maternal age, education, household wealth, employment status, residence, region, media exposure, sex of child, and birth order. Others variables include child's size at birth, parity, distance to health facility, antenatal care attendance, place of delivery, source of water, and toilet facility. Maternal age was measured as 15-24 years, 25-34 years, and 35 years and above. Education was categorised as none, primary and secondary/higher. Household wealth was defined as poorest, poorer, middle, richer, and richest. Employment status was defined as working and not working. Residence was grouped into urban and rural. Region was categorised as North-Central, North-East, North-West, South-East, South-South, and South-West. Media exposure was defined as exposed and not exposed.

Child's sex has two categories: male and female. Birth order was measured as first order birth, second order birth, and third or higher order birth. Child's size at birth was grouped into large, average, and small. Parity was measured as less than 5 and 5 or more. Distance to health facility was defined as problem for those who experienced difficulty getting to the facility and not a problem for those who did not experience any difficulty getting to the 
facility. Antenatal care attendance was categorised as attended and did not attended. Place of delivery was measured as home for women who delivered their babies at home and health facility for those who delivered at any health facility. Source of water and toilet facility were each grouped into improved and non-improved.

Independent variables

\section{Outcome variable}

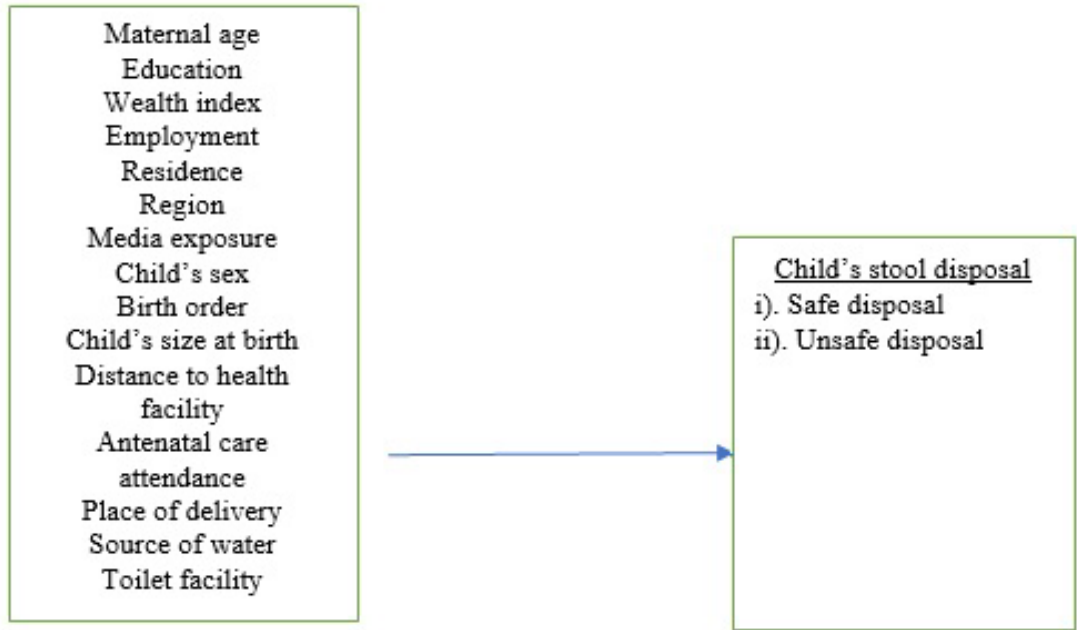

Figure 1. Conceptual framework showing the factors influencing child's stool disposal in Nigeria. Figure adapted from Nkoka (2020). Correlates of Appropriate Disposal of Children's Stool in Malawi: A Multilevel Analysis. BMC Public Health. 20: 1-10, 604

\section{Data Management and Analysis}

This study employed both descriptive and multivariate analysis. Descriptive analysis involves the use of number (frequencies) and percentages to describe the distribution of respondents' characteristics in relation to the outcome variable. Chi-Square test was used to examine the relationship between each independent variable and the outcome variable. In the multivariate analysis, binary logistic regression model was applied. It is a statistical technique used when the outcome variable is dichotomous while the independent variables may be of any type. In this study, the outcome variable was dichotomised as 1 for safe child's stool disposal and 0 for unsafe child's stool disposal. The binary logistic regression model is given as:

$$
\operatorname{logit}[\pi(x)]=\alpha+\beta_{1} X_{1}+\beta_{2} X_{2}+\cdots+\beta_{p} X_{p}
$$

Where $X_{1}, X_{2}, \ldots, X_{p}$ are independent variables and $\beta_{1}, \beta_{2}, \ldots, \beta_{p}$ are the logit coefficients of the independent variables (Liu, 2016). This model has also been applied by Nkoka (2020) using a multilevel approach.

Three $\alpha$ levels $(0.05,0.01$ and 0.001$)$ were specified to reflect the level of significance. All statistical operations were performed using Stata 14 
Statistical software (StataCorp, 2015). Variance inflation factor (VIF) was used to test for multicollinearity between or among the independent variables.

\section{Empirical Results \\ Descriptive Statistics}

Table 1 shows results from descriptive statistics. The study involved 7,834 children under age five. About 53\% of women reported that they disposed the stool of their children safely. This level is lower than the one reported by Nkoka (2020) in Malawi. While safe disposal of child's stool was highest among women aged 15-24 years (55\%), sixty-one percent (61\%) of women with no formal education reported that they safely disposed the stool of their children. A high proportion of women who disposed their children's stool were not working (61\%), were from middle wealth households (57\%), residing in Northwest (76\%), and were not exposed to media (55\%). Most of the children whose stool was safely disposed were of third or higher order birth (56\%) and were large in size at birth (56\%). Majority of the women whose children's stool was safely disposed posited that they do not experience any problem when seeking health service (58\%) and most of these women delivered at home. Most of the children whose mothers use improved toilet facility had their stool safely disposed.

Table 1. Prevalence of children's stool disposal by independent variables, NDHS 2018

\begin{tabular}{|c|c|c|c|c|}
\hline \multirow[t]{2}{*}{ Variable } & \multicolumn{4}{|c|}{ Children’s stool disposal status } \\
\hline & $\begin{array}{c}\text { Unsafe disposal } \\
\mathrm{N}(\%) \\
\end{array}$ & $\begin{array}{c}\text { Safe disposal } \\
\mathrm{N}(\%) \\
\end{array}$ & $\begin{array}{c}\text { Total } \\
\mathrm{N}(\%) \\
\end{array}$ & p-value \\
\hline \multicolumn{5}{|l|}{ Maternal age } \\
\hline $15-24$ & $883(44.8)$ & $1,090(55.2)$ & $1,973(100.0)$ & \\
\hline $25-34$ & 2,024 (47.7) & 2,216 (52.3) & $4,240(100.0)$ & \\
\hline $35+$ & $785(48.4)$ & $836(51.6)$ & $1,621(100.0)$ & 0.045 \\
\hline \multicolumn{5}{|l|}{ Education } \\
\hline None & $1,161(38.6)$ & $1,845(61.4)$ & $3,006(100.0)$ & \\
\hline Primary & 651 (51.2) & $620(48.8)$ & $1,271(100.0)$ & \\
\hline Secondary/higher & $1,880(52.9)$ & $1,677(47.1)$ & 3,557 (100.0) & $<0.001$ \\
\hline \multicolumn{5}{|l|}{$\begin{array}{l}\text { Household } \\
\text { wealth index }\end{array}$} \\
\hline Poorest & $826(51.5)$ & $777(48.5)$ & $1,603(100.0)$ & \\
\hline Poorer & 701 (44.9) & $861(55.1)$ & $1,562(100.0)$ & \\
\hline Middle & $741(43.1)$ & 980 (56.9) & $1,721(100.0)$ & \\
\hline Richer & 770 (46.7) & 878 (53.3) & 1,648 (100.0) & \\
\hline Richest & $654(50.3)$ & 646 (49.7) & $1,300(100.0)$ & $<0.001$ \\
\hline \multicolumn{5}{|l|}{ Employment } \\
\hline Not working & $1,030(39.3)$ & $1,592(60.7)$ & $2,622(100.0)$ & \\
\hline Working & 2,662 (51.1) & 2,550 (48.9) & $5,212(100.0)$ & $<0.001$ \\
\hline \multicolumn{5}{|l|}{ Residence } \\
\hline Urban & $1,454(48.5)$ & $1,546(51.5)$ & $3,000(100.0)$ & \\
\hline Rural & $2,238(46.3)$ & $2,596(53.7)$ & $4,834(100.0)$ & 0.061 \\
\hline Region & & & & \\
\hline
\end{tabular}




\begin{tabular}{|c|c|c|c|c|}
\hline North central & 812 (61.4) & $511(38.6)$ & $1,323(100.0)$ & \\
\hline North east & 452 (31.1) & 999 (68.9) & $1,451(100.0)$ & \\
\hline North west & $469(24.1)$ & 1,475 (75.9) & $1,944(100.0)$ & \\
\hline South east & $761(64.4)$ & $420(35.6)$ & $1,181(100.0)$ & \\
\hline South south & 510 (57.5) & 377 (42.5) & 887 (100.0) & \\
\hline South west & $688(65.6)$ & $360(34.4)$ & $1,048(100.0)$ & $<0.001$ \\
\hline \multicolumn{5}{|l|}{ Media exposure } \\
\hline Not exposed & 1,202 (44.9) & 1,477 (55.1) & 2,679 (100.0) & \\
\hline Exposed & $2,490(48.3)$ & $2,665(51.7)$ & $5,155(100.0)$ & 0.004 \\
\hline \multicolumn{5}{|l|}{ Child's sex } \\
\hline Male & $1,871(47.1)$ & 2,103 (52.9) & 3,974 (100.0) & \\
\hline Female & $1,821(47.2)$ & 2,039 (52.8) & $3,860(100.0)$ & 0.933 \\
\hline \multicolumn{5}{|l|}{ Birth order } \\
\hline $1^{\text {st }}$ order birth & 847 (51.7) & 791 (48.3) & 1,638 (100.0) & \\
\hline $2^{\text {nd }}$ order birth & $756(50.6)$ & 737 (49.4) & $1,493(100.0)$ & \\
\hline $\begin{array}{l}3^{\text {rd }} \text { or higher } \\
\text { order birth }\end{array}$ & $2,089(44.4)$ & $2,614(55.6)$ & $4,703(100.0)$ & $<0.001$ \\
\hline \multicolumn{5}{|l|}{$\begin{array}{l}\text { Child's size at } \\
\text { birth }\end{array}$} \\
\hline Large & 1,132 (43.9) & $1,444(56.1)$ & $2,576(100.0)$ & \\
\hline Average & $1,983(47.7)$ & $2,177(52.3)$ & $4,160(100.0)$ & \\
\hline Small & $577(52.6)$ & $521(47.5)$ & $1,098(100.0)$ & $<0.001$ \\
\hline \multicolumn{5}{|l|}{ Parity } \\
\hline Less than 5 & 2,449 (49.3) & $2,518(50.7)$ & $4,967(100.0)$ & \\
\hline $5+$ & $1,243(43.4)$ & $1,624(56.6)$ & $2,867(100.0)$ & $<0.001$ \\
\hline \multicolumn{5}{|l|}{ Distance to } \\
\hline A problem & 1,378 (59.3) & 945 (40.7) & $2,323(100.0)$ & \\
\hline Not a problem & $2,314(42.0)$ & 3,197 (58.0) & $5,511(100.0)$ & $<0.001$ \\
\hline \multicolumn{5}{|l|}{$\begin{array}{l}\text { Antenatal care } \\
\text { attendance }\end{array}$} \\
\hline Did not attend & $536(49.0)$ & $557(51.0)$ & $1,093(100.0)$ & \\
\hline Attended & $1,734(46.7)$ & 1,980 (53.3) & $3,714(100.0)$ & 0.171 \\
\hline \multicolumn{5}{|l|}{ Place of delivery } \\
\hline Home & $1,794(41.4)$ & $2,543(58.6)$ & 4,337 (100.0) & \\
\hline Health facility & $1,898(54.3)$ & $1,599(45.7)$ & $3,497(100.0)$ & $<0.001$ \\
\hline \multicolumn{5}{|l|}{ Source of water } \\
\hline Non-improved & $1,194(45.8)$ & $1,414(54.2)$ & $2,608(100.0)$ & \\
\hline Improved & $2,413(47.4)$ & $2,682(52.6)$ & $5,095(100.0)$ & 0.189 \\
\hline \multicolumn{5}{|l|}{ Toilet facility } \\
\hline Non-improved & $2,051(56.1)$ & 1,608 (43.9) & 3,659 (100.0) & \\
\hline Improved & $1,556(38.5)$ & $2,488(61.5)$ & $4,044(100.0)$ & $<0.001$ \\
\hline
\end{tabular}

\section{Correlates of Safe Stool Disposal in Nigeria}

Results from multivariate analysis (Table 2) show that household wealth is significantly associated with safe disposal of child's stool. From the multivariable analysis and focusing on the purpose of this study, children from the richest households are $97 \%$ more likely to have their stool safely disposed 
than children from poorest households. The likely reasons for this finding are intuitively situated in the fact that such women have easy access to modern housing and toilets facilities within the context of resources available to them in such households. This of course is in line with the finding of Bawankule et al. (2017).

Children of working women are $17 \%$ less likely to have their stool safely disposed than children of non-working women. There is the need to bear in mind that many Nigerian women are engaged in the informal sector of the economy, working as petty-traders and other related-businesses. This in turn puts a lot of restriction on their access to modern toilet facilities where they can safely dispose their children's stool, bearing in mind the deficit in the provision of public infrastructures in the country. Regions has been found to influence safe stool disposal as results indicate that children from Northeast and Northwest are more likely to have their stool safely disposed compared with children from North Central. However, children from Southeast and Southwest are less likely to have their stool safely disposed. This finding is counter-intuitive because it is expected that Southwest and Southeast regions should perform better in relation to this indicator because of higher level of education and supposed better exposure. However, presence of international organisations, non-governmental organisations, and civil society groups together with the intervention programmes going on in many parts of the Northern regions could be responsible for this kind of finding. Nkoka (2020) found a similar trend in Malawi where region was a significant factor in the appropriate disposal of children's stool.

The odds of having stool safely disposed increased by $19 \%$ for children whose mothers were exposed to media. Expectedly, mothers exposed to mass media would have been exposed one way or the other to the appropriate information, education and communication (IEC) programmes which could have influenced their behaviour positively. This finding is in line with similar studies in other climes (Bawankule et al., 2017; Nkoka 2020). Considering birth order, results show that the odds of having child's stool safely disposed decreased by $24 \%$ for children of first order birth compared to children of third or higher order birth. This may be as a result of lack of experience on the part of the mothers having their first birth within the study period. It is expected that women with higher birth order will be older and would have gathered enough experience through various public enlightenment programmes which could assist in the safe disposal of their children's stool in the study area.

Children who were small at birth are $31 \%$ less likely to have their stool safely disposed compared to children who were large at birth. This could be an indication of deprivation at the individual and household level right from birth which invariably translates to the denial of access to basic facilities needed for safe disposal of stools. With respect to ease of access to health 
facility, children of women who claimed that getting to health facility was not a problem are $66 \%$ more likely to have their stool safely disposed. The likely reason for this finding is IEC programmes' impact on such women could assist them in appreciating and practising better sanitation with regard to the subjectmatter. Such IEC programmes designed and made available to women during antenatal attendance could have raised their level of awareness thereby leading to safe stool disposal in the study area. This finding is in line with the recent study conducted in Malawi by Nkoka (2020).

The odds of safe stool disposal increased by $114 \%$ for children whose mothers make use of improved toilet facility, while it reduced by $19 \%$ for children whose mothers delivered at a health facility. This finding makes sense within the context of mother's access to improved toilet facility since it will automatically translate to such women using such for their children. This conforms to earlier findings by Aliyu and Tukur (2019) and Nkoka (2020). However, considering the place of delivery for the children in question, the odds of safe stool disposal reduced by $19 \%$ for children whose mothers delivered at a health facility. The likely explanation here is that such health facilities are not their permanent place of abode. This is because those mothers will move to their various homes immediately after child-birth if there are no complications. Thus, where they stay permanently is where the action would usually take place.

Table 2. Logistic regression of correlates of safe disposal of children's stool in Nigeria, NDHS 2018

\begin{tabular}{|c|c|}
\hline Variable & $\begin{array}{c}\text { Safe disposal of children's stool } \\
\text { aOR }(95 \% \mathrm{CI})\end{array}$ \\
\hline \multicolumn{2}{|l|}{ Maternal age } \\
\hline $15-24$ & 1 \\
\hline $25-34$ & $0.87(0.72-1.04)$ \\
\hline $35+$ & $0.95(0.74-1.21)$ \\
\hline \multicolumn{2}{|l|}{ Education } \\
\hline None & 1 \\
\hline Primary & $1.09(0.87-1.38)$ \\
\hline Secondary/higher & $1.08(0.86-1.36)$ \\
\hline \multicolumn{2}{|c|}{ Household wealth index } \\
\hline Poorest & 1 \\
\hline Poorer & $1.54 * * *(1.24-1.91)$ \\
\hline Middle & $2.14 * * *(1.67-2.76)$ \\
\hline Richer & $2.33 * * *(1.73-3.13)$ \\
\hline Richest & $1.97 * * *(1.41-2.76)$ \\
\hline \multicolumn{2}{|l|}{ Employment } \\
\hline Not working & 1 \\
\hline Working & $0.83 *(0.72-0.96)$ \\
\hline \multicolumn{2}{|l|}{ Residence } \\
\hline Urban & $0.95(0.80-1.12)$ \\
\hline Rural & 1 \\
\hline Region & \\
\hline
\end{tabular}


North central

North east

North west

South east

South south

South west

Media exposure

Not exposed

Exposed

Child's sex

Male

Female

Birth order

$1^{\text {st }}$ order birth

$2^{\text {nd }}$ order birth

$3^{\text {rd }}$ or higher order birth

Child's size at birth

Large

Average

Small

Parity

Less than 5

$5+$

Distance to health facility

A problem

Not a problem

Antenatal care attendance

Did not attend

Attended

Place of delivery

Home

Health facility

\section{Source of water}

Non-improved

Improved

Toilet facility

Non-improved
1

4.32*** (3.39-5.50)

6.59*** (5.19-8.36)

$0.66 * *(0.52-0.84)$

$0.90(0.71-1.15)$

$0.55^{* * *}(0.44-0.70)$

1

$1.19 *(1.01-1.41)$

$1.03(0.91-1.17)$

1

$0.76 *(0.61-0.94)$

0.84 (0.69-1.02)

1

1

$0.99(0.86-1.14)$

$0.69 * * *(0.56-0.84)$

$1.09(0.91-1.32)$

1

1

$1.66^{* * *}(1.43-1.93)$

1

1.15 (0.97-1.37)

1

$0.81 *(0.69-0.96)$

1

$1.06(0.89-1.24)$

1

$2.14 * * *(1.82-2.52)$

Significant at ${ }^{* * *} \mathrm{p}<0.001 ;{ }^{* *} \mathrm{p}<0.01 ;{ }^{*} \mathrm{p}<0.05$ Reference Category=1.00, Figures in parentheses are Confidence Intervals, aOR= adjusted Odds Ratio

Results from Table 3 show that VIF for the independent variables ranges from 1.01 to 2.85 with the mean VIF being 1.50 . Since the values are less than 10, it implies that there is no multicollinearity, that is, there is no perfect linear combination among the independent variables.

Table 3. Results of multicollinearity on correlates of child's safe stool disposal in Nigeria 


\begin{tabular}{cccc}
\hline Maternal age & 1.78 & 1.34 & 0.5607 \\
Education & 2.09 & 1.44 & 0.4792 \\
Wealth index & 2.85 & 1.69 & 0.3506 \\
Employment & 1.11 & 1.05 & 0.8988 \\
Residence & 1.42 & 1.19 & 0.7024 \\
Region & 1.27 & 1.13 & 0.7899 \\
Media exposure & 1.47 & 1.21 & 0.6792 \\
Child's sex & 1.01 & 1.00 & 0.9942 \\
Birth order & 1.61 & 1.27 & 0.6205 \\
Child's size at birth & 1.01 & 1.01 & 0.9871 \\
Parity & 1.69 & 1.30 & 0.5922 \\
Distance to health & 1.12 & 1.06 & 0.8906 \\
facility & & & \\
Antenatal care & 1.27 & 1.13 & 0.7872 \\
attendance & & & \\
Place of delivery & 1.53 & 1.24 & 0.6552 \\
Source of water & 1.32 & 1.15 & 0.7601 \\
Toilet facility & 1.49 & 1.22 & 0.6710 \\
Mean VIF & 1.50 & & \\
\hline
\end{tabular}

VIF: Variance inflation factor

\section{Conclusion and Policy Implications}

This study concludes that household wealth index, women's working status, region of residence, women's exposure to mass media, birth order of the child, child's birth weight at birth, access to health facility, and mother's use of improved toilet facility were the correlates of safe disposal of stool among women with under-five children in Nigeria. Hence, these factors should therefore be prioritised for interventions aimed at reducing high underfive morbidity and mortality in Nigeria. The policy implications of this study are as follows: One, improving the economic welfare of individuals and Nigerian households are imperative for the overall health of under-five children and the government at all levels must make it a priority. Two, provision of public physical infrastructures such as public toilets should be embarked upon by the government at all levels. Three, interventions aimed at improving the health status of under-five children in Nigeria should be regionsensitive with particular emphasis on Southeast and Southwest that are lagging behind in this area. Four, strategic programmes should be constantly aired through the mass media in order to educate Nigerians on the negative consequences of improper handling of children's stool. Five, younger and perhaps inexperienced women should be targeted with appropriate IEC programmes that will impart skills to them for better performance in childcare. Six, making health facilities easily accessible to the populace will invariably improve the health status of U5 children indirectly. Seven, Town Planning Officers and Sanitary Inspectors should be empowered to enforce 
building standards in Nigeria since toilet facilities is an integral part of any building project anywhere in the world.

\section{References:}

1. Aliyu, A. A., \& Dahiru, T. (2019). Factors Associated with Safe Disposal Practices of Child's Faeces in Nigeria: Evidence from 2013 Nigeria Demographic and Health Survey. Nigerian Medical Journal, 60(4), 198-204. https://doi.org/10.4103/nmj.NMJ_3_19

2. Bawankule, R., Singh, A., Kumar, K. et al. (2017). Disposal of children's stools and its association with childhood diarrhea in India. BMC Public Health 17, 12 https://doi.org/10.1186/s12889-016-3948-2

(2017).

3. Ferede, M.M. (2020). Socio-demographic, environmental and behavioural risk factors of diarrhoea among under-five children in rural Ethiopia: further analysis of the 2016 Ethiopian demographic and health survey. BMC Pediatr 20, 239 (2020). https://doi.org/10.1186/s12887-020-02141-6

4. Liu, X. (2016). Applied Ordinal Logistic Regression Using Stata: From Single-Level to Multilevel Modeling. https://us.sagepub.com/en-us/nam/applied-ordinal-logisticregression-using-stata/book243480Applied. U. S. A.: SAGE Publications Ltd.

5. Mulatya, D.M., \& Ochieng, C. (2020). Disease burden and Risk Factors of diarrhoea in children under five years: Evidence from Kenya's demographic health survey 2014, International Journal of Infectious Diseases

(2020). https://doi.org/10.1016/j.ijid.2020.02.003

6. National Bureau of Statistics (2018). Demographic Statistics Bulletin. National Bureau of Statistics, May 2018 retrieved at https://nigerianstat.gov.ng/download/775 on 07/07/2020.

7. Nkoka, O. (2020). Correlates of appropriate disposal of children's stools in Malawi: a multilevel analysis. BMC Public Health 20, 604 (2020). https://doi.org/10.1186/s12889-02008725-2

8. NPC \& ICF (2019). Nigeria Demographic and Health Survey 2018. DHS Program ICF, Rockville, Maryland USA. https://www.dhsprogram.com/pubs/pdf/FR359/FR359.pdf

9. Omona, S., Malinga, G.M., Opoke, R. et al. (2020). Prevalence of diarrhoea and associated risk factors among children under five years old in Pader District, northern Uganda. BMC Infect Dis 20, 37 (2020). https://doi.org/10.1186/s12879-020-4770-0 
10. Onyilokwu, S. A., Aye, A. M., Adamu, S. G., \& Lawan, F. A. (2020). Epidemiological and demographic factors associated with diarrhoea in Makurdi, Benue State, Nigeria. Journal of Public Health and Epidemiology, 12(2), 98-105. https://doi.org/10.5897/JPHE2020.1225

11. StataCorp (2015). Stata Statistical Software, Release 14. College Station, TX: StataCorp LP.

12. UNICEF (2020). UNCEF Data: Monitoring the situation of children and women. https://data.unicef.org/resources/data_explorer/unicef_f/?ag=UNI CEF\&df=GLOBAL_DATAFLOW\&ver $=1.0 \& d q=N G A . C M E \_M$ RY0T4.\&startPeriod=1970\&endPeriod=2020. Accessed July 04, 2020.

13. WHO/UNICEF (2006). Core Questions on Drinking-Water and Sanitation for Household Surveys. Geneva: World Health Organisation and UNICEF; 2006. https://www.who.int/water_sanitation_health/monitoring/oms_br ochure_core_questionsfinal24608.pdf accessed 29 June 2020.

14. World Health Organization (2015(. Health in 2015: from MDGs, Millennium Development Goals to SDGs, Sustainable Development Goals. World Health Organization. https://apps.who.int/iris/handle/10665/200009

15. World Population Review (2020). Nigeria Population 2020 (Live) accessed at https://worldpopulationreview.com/count on 07/07/2020

16. You, D., Hug, L. \& Chen, Y. (2014). Levels \& Trends in Child Mortality: Report 2014, Estimates Developed by the UN Interagency Group for Child Mortality Estimation: United Nations Inter-agency Group for Child Mortality Estimation (UN-IGME). A UNICEF

Report. https://www.unicef.org/media/files/Levels_and_Trends_in_Child _Mortality_2014.pdf 